University of Wollongong

Research Online

Faculty of Social Sciences - Papers (Archive) Faculty of Arts, Social Sciences \& Humanities

$1-1-2018$

Cardiorespiratory Fitness and Blood Pressure: A Longitudinal Analysis

Cesar A. Agostinis-Sobrinho

University of Porto

Jonatan R. Ruiz

University of Granada

Carla Moreira

University of Porto

Sandra Abreu

University of Porto

Luis C. Oliveira Lopes

University of Porto, luisl@uow.edu.au

See next page for additional authors

Follow this and additional works at: https://ro.uow.edu.au/sspapers

Part of the Education Commons, and the Social and Behavioral Sciences Commons

Research Online is the open access institutional repository for the University of Wollongong. For further information contact the UOW Library: research-pubs@uow.edu.au 


\title{
Cardiorespiratory Fitness and Blood Pressure: A Longitudinal Analysis
}

\begin{abstract}
OBJECTIVES: To examine the association between cardiorespiratory fitness and cardiovascular indices 2 years later, and to determine whether changes in cardiorespiratory fitness are associated with cardiovascular indices at a 2-year follow-up in adolescents. STUDY DESIGN: The sample comprised 734 adolescents (349 girls) aged 12-18 years followed for 3 years from the LabMed Physical Activity Study. Cardiorespiratory fitness was assessed by the 20-meter shuttle run test. Height, weight, waist circumference, and resting blood pressure (BP) were measured according to standard procedures. RESULTS: Regression analyses showed a significant inverse association between cardiorespiratory fitness at baseline and systolic $B P(B=-0.126 ; P=.047)$ and rate pressure product $(B=-29.94 ; P=.016)$, at follow-up after adjustments for age, sex, height, pubertal stage, socioeconomic status, and waist circumference. Significant differences were found between cardiorespiratory fitness groups (fit vs unfit) at baseline and systolic BP and rate pressure product at follow-up $(\mathrm{P}<.05$ for all). Analysis of covariance showed a significant association between cardiorespiratory fitness changes and systolic BP $(P=.024)$ and rate pressure product $(P=.014)$, after adjustment for age, sex, height, pubertal status, socioeconomic status, and waist circumference. CONCLUSIONS: Changes in cardiorespiratory fitness during adolescence were associated with cardiovascular indices over a 2-year period. Adolescents with persistently low levels of cardiorespiratory fitness exhibited the highest levels of systolic BP and rate pressure product.

Disciplines

Education | Social and Behavioral Sciences

Publication Details

Agostinis-Sobrinho, C., Ruiz, J. R., Moreira, C., Abreu, S., Lopes, L., Oliveira-Santos, J., Mota, J. \& Santos, R. (2018). Cardiorespiratory Fitness and Blood Pressure: A Longitudinal Analysis. Journal of Pediatrics, 192 130-135.
\end{abstract}

\section{Authors}

Cesar A. Agostinis-Sobrinho, Jonatan R. Ruiz, Carla Moreira, Sandra Abreu, Luis C. Oliveira Lopes, Jose Oliveira-Santos, Jorge Mota, and Rute Santos 


\title{
Cardiorespiratory fitness and blood pressure, a longitudinal analysis: the LabMed
} Physical Activity Study

\author{
César Agostinis-Sobrinho ${ }^{1}$, MSc; Jonatan R. Ruiz ${ }^{2}$, PhD; Carla Moreira ${ }^{1}, \mathrm{PhD}$; \\ Sandra Abreu ${ }^{1}, \mathrm{PhD}$; Luís Lopes ${ }^{1}, \mathrm{PhD}$; José Oliveira-Santos ${ }^{1}, \mathrm{MSc}$; Jorge Mota ${ }^{1}, \mathrm{PhD}$; \\ Rute Santos ${ }^{1,3}, \mathrm{PhD}$. \\ ${ }^{1}$ Research Centre in Physical Activity, Health and Leisure, Faculty of Sport, University \\ of Porto, Portugal. \\ 2 PROFITH "PROmoting FITness and Health through physical activity" Research \\ Group, Department of Physical Education and Sport, Faculty of Sport Sciences, \\ University of Granada, Granada, Spain. \\ ${ }^{3}$ Early Start Research Institute, Faculty of Social Sciences, School of Education. \\ University of Wollongong, Australia.
}

Statement of honorarium, grant, or other form of payment: The author César A. Agostinis Sobrinho wrote the first draft of the manuscript and was given Doctoral scholarship from Brazilian government by CAPES (Coordination of Improvement of Higher Education Personnel) (Proc: 9588-13-2). This study was supported by FCT grants: BPD/102381/2014 and BD88984/2012; The Research Centre on Physical Activity Health and Leisure (CIAFEL) is supported by UID/DTP/00617/2013 (FCT). Rute Santos has a Discovery Early Career Research Award from the Australian Research Council (DE150101921). Luis Lopes has an Endeavour Research Fellowship 6072_2017 from the Australian Research Council. The authors declare that they have no conflicts of interest.

*Reprint requests: César A. Agostinis Sobrinho. Research Centre in Physical Activity, Health and Leisure. Faculty of Sport - University of Porto. Rua Dr. Plácido Costa, 91. 4200-450 Porto. Phone number: 00351225074786 .Fax number: 00351 225500689. Email : cesaragostinis@ hotmail.com 
Running title: Cardiorespiratory fitness and blood pressure

\begin{abstract}
Objectives: This study aimed i) to examine the association between cardiorespiratory fitness and cardiovascular indexes 2 years later; (ii) to determine whether changes in cardiorespiratory fitness are associated with cardiovascular indexes at 2-yr follow-up, in adolescents.
\end{abstract}

SUBJECTS/METHODS: The sample comprised 734 adolescents (349 girls) aged from 12-18 followed 3 yr from the LabMed Physical Activity Study.

Results: Cardiorespiratory fitness was assessed by 20 meters' shuttle run test. Height, weight, waist circumference and resting blood pressure (BP) were measured according to standard procedures. Regression analyses showed a significant inverse association between cardiorespiratory fitness at baseline and systolic BP ( $\mathrm{B}=-0.126 ; p=0.047)$ and rate pressure product ( $\mathrm{B}=-29.94 ; p=0.016$ ), at follow up after adjustments for age, sex, height, pubertal stage, socioeconomic status and waist circumference. Significant differences between cardiorespiratory fitness groups (Fit vs Unfit) at baseline and systolic BP and rate pressure product at follow up ( $<<0.05$ for all) were found. Regarding the cardiorespiratory fitness-change categories, analysis of covariance showed a significant association between cardiorespiratory fitness-changes and systolic BP $(p=0.024)$ and rate pressure product $(p=0.014)$, after adjustment for and age, sex, height, pubertal status, socioeconomic status and waist circumference.

Conclusions: Changes in cardiorespiratory fitness during adolescence were associated with cardiovascular indexes over a two-year period: adolescents with persistently low levels of cardiorespiratory fitness exhibited the highest levels of systolic BP and rate pressure product.

KEYWORDS: blood pressure, aerobic fitness changes, youth. 


\section{Introduction}

Globally, cardiovascular disease accounts for approximately 17 million deaths annually (1), and hypertension is responsible for at least 45 percent of deaths due to heart disease every year (1). The prevalence of raised blood pressure (BP) in children and adolescents has become a significant public health issue (2). BP seems to track from childhood to adulthood, and an elevated BP during childhood is likely to predict adult hypertension (3). Hypertension seems to be one of the major modifiable risk factors for cardiovascular disease with roots in childhood $(3,4)$, and therefore, studies are needed to identify the determinants of BP tracking in childhood and adolescence (3).

Findings from cross-sectional studies in adolescents have shown that low cardiorespiratory fitness is inversely associated with increased BP $(5,6)$. In addition, longitudinal studies have shown that a high level of fitness in childhood is associated with lower BP in adulthood $(7,8)$. Kvaavik and colleagues reported that physical fitness levels at the age of 13 years were inversely related to systolic and diastolic BP two years later (9). However, it is of interest to the public's health to better understand how changes in cardiorespiratory fitness during adolescence correlate to BP later in life.

The aims of this study were: (i) to examine the association between cardiorespiratory fitness and cardiovascular indexes two years later; and (ii) to determine whether changes in cardiorespiratory fitness are associated with cardiovascular indexes at a two-year follow-up in a sample of adolescents.

\section{Methods}

\section{Study Design and Sample}

The current study is part of the "Longitudinal Analysis of Biomarkers and Environmental Determinants of Physical Activity (LabMed Physical Activity Study)”, a school-based cohort carried out in the Northern Region of Portugal, which aimed to 
evaluate the independent and combined associations of dietary intake and fitness levels on cardiometabolic risk factors. Detailed description of sampling and recruitment approaches, data collection, analysis strategies have been described elsewhere $(10,11)$. In short, selection of schools was based on pragmatic, budgetary and logistical reasons. Thus, a total of 5 schools were randomly selected within those which had previous collaboration agreements established with our research centre and fitted the abovementioned criteria. Baseline data was collected in 2011 for 1,229 adolescents aged 12 to-18 years 1,011 and 789 subjects were reevaluated 1 and 2 years later, respectively. Of those, a total of 734 adolescents (349 girls), that had complete data at baseline and $2 \mathrm{yr}$ follow-up on the variables of interest, were included in the present study. None of the subjects were taking any medication or had any clinically manifest illness. The participants were informed and advised to abstain of alcohol, tobacco and from any exercise minimum 24 hrs before tests. Throughout the study no exclusion criteria was applied to avoid discriminations. However, for the present analysis only apparently healthy adolescents were considered.

The protocol was conducted according to the World Medical Association's Helsinki Declaration for Human Studies. The Portuguese Data Protection Authority (\#1112434/2011), the Portuguese Ministry of Science and Education (0246200001/2011) and Faculty of Sport, University of Porto, approved the study. All participants in this study were informed of the study's aims, and written informed consent was obtained from participating adolescents and their parents or guardians.

\section{Measures}

\section{Cardiorespiratory Fitness}

Cardiorespiratory fitness was assessed with the 20-metre Shuttle Run Test (20 m SRT) (12). This test is arguably the most popular field-based assessment to estimate of 
cardiorespiratory fitness in children and youth worldwide (13). This test requires participants to run back and forth between two lines set $20 \mathrm{~m}$ apart. Running speed started at $8.5 \mathrm{~km} / \mathrm{h}$ and increased by $0.5 \mathrm{~km} / \mathrm{h}$ each minute, reaching $18.0 \mathrm{~km} / \mathrm{h}$ at minute 20. Each level was announced on a tape player. The participants were instructed to keep up with the pace until exhausted. The test was finished when the participant failed to reach the end lines concurrent with the audio signals on two consecutive occasions. Otherwise, the test ended when the subject stopped because of fatigue. The participants received verbal encouragements from the investigators to achieve maximum performance, i.e. to keep running as long as possible. The test was performed once, and the number of shuttles performed by each participant was recorded to posterior calculation of $\mathrm{VO}_{2 \max }$ using Léger's equations (12). Adolescents were also classified in two groups (Fit and Unfit) according to specific cut points for adolescents (14).

\section{Blood Pressure}

Blood pressure was measured according to the procedures recommended in the literature (15-17). Blood pressure was measured using a Dynamap vital signs monitors (model BP 8800, Critikon, Inc., Tampa, Florida). Appropriate cuff size matched to the size of the child's extremity was used (15). Trained nurses took measurements, and all adolescents were required to sit and rest for at least $5 \mathrm{~min}$ prior to the first blood pressure measurement. Participants were in a seated, relaxed position with their feet resting flat on the ground. Two measurements in the non-dominant arm were taken, after five and 10 min of rest and abstinence from coffee, tobacco or alcohol. The mean of these two measurements was considered. If the two measurements differed by 10 $(\mathrm{mmHg})$ or more, a third measure was taken and the first one discarded (17). This approach was used in a previous studies in a population with similar 
characteristics $(18,19)$. The rate pressure product was calculated as (heart rate $\times$ systolic BP) and pulse pressure was defined as the difference between systolic BP and diastolic BP.

\section{Socioeconomic Status}

The socioeconomic status was assessed with the Family Affluence Scale (20), developed specifically to measure children and adolescents socio-economic status in the context of the Health Behaviour in School-Aged Children Study.

\section{Anthropometrics}

Body height was measured to the nearest $0.1 \mathrm{~cm}$ in bare or stocking feet with the adolescent standing upright against a portable stadiometer (Seca213, Hamburg, Germany). Body weight was measured to the nearest $0.10 \mathrm{~kg}$, lightly dressed, with no shoes, using a portable electronic weight scale (Tanita Inner Scan BC532, Tokyo, Japan)(21). Body mass index (BMI) was calculated as the ratio of body weight $(\mathrm{kg})$ to body height $\left(\mathrm{m}^{2}\right)$ and adolescents were classified according to Cole's body mass index categories (22). Waist Circumference (WC) measurements were taken midway between the lower rib margin and the anterior superior iliac spine at the end of normal expiration following standard procedures (21).

\section{Pubertal stage}

Self-assessment was performed by having participants choose the specific pictures for Tanner stages of sexual maturation that best described their current stage of development (breast and pubic hair development in girls and genital and pubic hair development in boys ranging from stage I to V), according to the criteria of Tanner and Whitehouse $(23,24)$. 


\section{Statistics Analysis}

Descriptive data of baseline participants' characteristics are shown as means and standard deviations. Paired t-test were performed to access differences between baseline and follow-up variables.

Aim 1: To examine the association between cardiorespiratory fitness at baseline and cardiovascular indexes 2 years later, we performed multiple linear regression analyses. Systolic and diastolic BP, pulse pressure and rate pressure product at baseline and follow-up were entered as dependent variables in separate models, cardiorespiratory fitness at baseline as independent variable and age, sex, height, pubertal stage, socioeconomic status and waist circumference as covariates. These analyses were additionally controlled for the corresponding baseline value of the dependent variable. We also conducted analysis of covariance (ANCOVA) to study differences on Systolic and diastolic BP, pulse pressure and rate pressure product at follow-up by cardiorespiratory fitness levels at baseline (high vs. low). Systolic and diastolic BP, pulse pressure and rate pressure product at follow-up were entered as dependent variables, in separate models, cardiorespiratory fitness (Fit vs. Unfit) was entered as an independent variable, and age, sex, height, pubertal stage, socioeconomic status and waist circumference at baseline as covariates. These analyses were additionally controlled for the corresponding baseline value of the dependent variable.

Aim 2: To determine whether changes in cardiorespiratory fitness (from baseline to follow-up) is associated with cardiovascular indexes in adolescents at follow-up. We computed a cardiorespiratory fitness variable as follows: adolescents who were in the Unfit category both at the baseline and follow-up were classified as "persistent low fitness", and those who dropped from Fit category at baseline to Unfit category at follow-up were classified as "decreasing fitness". The other categories were "persistent 
high fitness" (Fit category at both baseline and follow-up), and "increasing fitness", those who changed from Unfit category at baseline to Fit category at follow-up. The association of cardiorespiratory fitness-change (persistent low, decreasing, persistent high, and increasing) categories with cardiovascular indexes at follow-up was assessed by ANCOVA. The cardiovascular indexes at follow-up were entered as dependent variables, in separate models, cardiorespiratory fitness-change categories as an independent variable, and age, sex, height, pubertal stage, socioeconomic status and waist circumference at baseline as covariates. These analyses were additionally controlled for the corresponding baseline value of the dependent variable.

\section{Results}

The general sample features are shown in Table 1. Boys and girls increase the number of shuttles over a two-year period $(\mathrm{p}<0.05)$. Boys showed lower levels of diastolic BP, pulse pressure and rate pulse pressure at follow-up; whereas girls showed lower levels of systolic BP, diastolic BP and rate pulse pressure at follow-up $(\mathrm{p}<0.05$ for all).

****INSERT TABLE $1 * * * *$

Regression analyses showed a significant inverse association between cardiorespiratory fitness at baseline and systolic $\mathrm{BP}(\mathrm{B}=-0.126 ; p<0.047)$, and rate pressure product $(\mathrm{B}=-29.94 ; p=0.016)$, at follow-up, after adjustments for age, sex, height, pubertal stage, socioeconomic status and waist circumference (Table 2, model 2). 
ANCOVA (Fig.1) showed significant differences between cardiorespiratory fitness groups (Fit vs Unfit) at baseline and systolic BP and rate pressure product at follow up ( $\mathrm{p}<0.05$ for all) after adjustment for sex, age, height, pubertal status, socioeconomic status, waist circumference and additionally, adjusted for the corresponding baseline levels of the dependent variable - model 2.

$* * * *$ INSERT FIGURE $1 * * * *$

Figure 2 shows the association of cardiorespiratory fitness-change categories with cardiovascular indexes at follow-up. ANCOVA showed significant differences between Persistent Low and Persistent High groups on Systolic BP $\left(F_{(3,723)}=4.96\right.$ $p=0.002)$, diastolic BP $\left(\mathrm{F}_{(3,723)}=2.66 p=0.047\right)$ and rate pressure product $\left(\mathrm{F}_{(3,723)}=\right.$ 6.98, $p<0.001$ ) after adjustment for and age, sex, height and pubertal status, socioeconomic status and additionally, adjusted for the corresponding (dependent variable) baseline levels (models 1). When waist circumference at follow-up was included (models 2), these differences between groups remain significant only for systolic $\mathrm{BP}\left(\mathrm{F}_{(3,723)}=3.16, p=0.024\right)$ and rate pressure product $\left(\mathrm{F}_{(3,723)}=3.54, p=0.014\right)$.

**** INSERT FIGURE 2****

\section{Discussion}

The main findings of the present longitudinal study in adolescents indicate that: Levels of cardiorespiratory fitness at baseline are inversely associated with systolic BP and rate pressure product at follow-up (two years later) after adjustments for age, sex, 
height, pubertal stage, socio-economic status and waist circumference. We also observed that adolescents with higher cardiorespiratory fitness at baseline had lower systolic BP and rate pressure product at follow-up than those with lower cardiorespiratory fitness. Importantly, two-year changes in cardiorespiratory fitness are associated with systolic BP and rate pressure product at follow-up adjusted for potential confounders. Our findings underscore the potential modifying effect of cardiorespiratory fitness on the BP trajectory over adolescence. The maintenance of adequate cardiorespiratory fitness levels might extend normal BP ranges, delaying the development of hypertension later in life.

These findings were consistent with previous cross-sectional studies showing that diastolic and systolic BP were significantly associated with cardiorespiratory fitness (5). A five-year longitudinal study with 125 subjects who were 10 years old at baseline reported that improvements in cardiorespiratory fitness and muscular strength during childhood led to a more favourable systolic BP in adolescence (25). However, in a twenty-year follow-up from adolescence, similar although nonsignificant trends were observed for cardiorespiratory fitness vs BP (4).

The mechanism by which cardiorespiratory fitness provides differential benefits for BP among adolescents is not yet clear (26). This is in large part due to the fact that the etiology of raised BP is multifactorial in nature, and it is not clear how these factors interact and contribute to the development of hypertension $(3,27)$. Nevertheless, it is known that cardiorespiratory fitness can be modified by exercise training and may prevent increases in BP through beneficial alterations in insulin sensitivity, endothelial function, and autonomic nervous system function (26).

Our results also highlight the potential effect of visceral adiposity in BP values. When our analyses were adjusted for waist circumference, the association between 
cardiorespiratory fitness and cardiovascular indexes did not remain significant for diastolic BP. Our results are partially in agreement with several cross-sectional studies that examined the mediation effect of adiposity in a relationship between cardiorespiratory fitness and BP in children (28) and young adults (29), and showed that measures of body composition acted as mediators between cardiorespiratory fitness and BP. Indeed, it is known that excessive adiposity is a strong determinant of hypertension in adults (30) as well as in children and adolescents (31). However, interestingly, in the analysis (ANCOVA) of cardiorespiratory fitness changes, our results remain significant for systolic BP and rate pressure product even when adjusted for waist circumference. These results have a higher clinical significance since elevated BP during childhood is likely to predict adult hypertension (3), and it seems to be an independent prognostic indicator of adult cardiovascular risk (32). The clear pattern for increased cardiovascular indexes among our sample suggests that persistent, low cardiorespiratory fitness across adolescence may pose a real health hazard.

Our findings have important clinical and public health implications for the prevention of cardiovascular diseases, especially those related to high BP. Since the evidence for a specific BP goal in children is scarce, and there is uncertainty as to the relative roles of BP targets and drug-specific effects on cardiovascular and renal outcomes (2), the findings of the present study suggest that cardiorespiratory fitness plays an important role in BP during adolescence. Despite guideline recommendations, most of the population fails to adopt or achieve an optimal number of healthy behaviors that help to prevent hypertension. These results provide an important public health message and suggest that not only should achieving normal-weight status be the primary goal for hypertension prevention but also needed are improvements in cardiorespiratory fitness to maintain optimal blood pressure among youth. 
A major strength of the present study is its longitudinal design, allowing us to evaluate the associations between cardiovascular indexes and cardiorespiratory fitness changes in a prospective study with a two-year follow-up. Other strengths are the large sample size and the fact that our analysis took into consideration important confounders such as pubertal status and waist circumference. The cardiorespiratory fitness test used in our study have been shown to be valid, reliable and feasible for health monitoring purposes in adolescents and is suitable for mass testing as it is simple, economical and easy to administer $(13,14)$. In addition, we classified the participants in two cardiorespiratory fitness groups according to the sex-specific cut-off points recently proposed (14). Limitations of the current study include the fact that our sample comprises predominantly healthy adolescents within the middle and higher socioeconomic strata. We also can't comment on whether our data accurately reflects the true BP status of the participants as it was only measured on one occasion each year. This point must be taken into consideration when interpreting our results.

In conclusion, changes in cardiorespiratory fitness during adolescence were associated with cardiovascular indexes over a two-year period: adolescents with persistently low levels of cardiorespiratory fitness exhibited the highest levels of systolic BP and rate pressure product.

\section{ACKNOWLEDGEMENTS}

The authors gratefully acknowledged the participation of all adolescents and their parents, teachers and schools of the LabMed Study. They also acknowledge the cooperation of volunteer's subjects and the Research Centre in Physical Activity, Health and Leisure (University of Porto) for the sponsoring the LabMed Study. 


\section{References}

1. World Health Organization (WHO). (2013). World Health Day 2013 [Internet]. A Global Brief on Hypertension: Silent Killer, Global Public Health Crisis [Online]. 2013. Available from: http://www.thehealthwell.info/node/466541 [Accessed: 22nd November 2016]

2. Lurbe E, Agabiti-Rosei E, Cruickshank JK, Dominiczak A, Erdine S, Hirth A, et al. 2016 European Society of Hypertension guidelines for the management of high blood pressure in children and adolescents. J Hypertens. 2016;34(10):1887920.

3. Chen X, Wang Y, Chen, Xiaoli and YW, Chen X, Wang Y. Tracking of blood pressure from childhood to adulthood: A systematic review and meta-regression analysis. Circulation. 2008;117(25):3171-80.

4. Kelly RK, Thomson R, Smith KJ, Dwyer T, Venn A, Magnussen CG. Factors Affecting Tracking of Blood Pressure from Childhood to Adulthood: The Childhood Determinants of Adult Health Study. J Pediatr. 2015;167(6):14221428.e2.

5. Klasson-Heggeb $\varnothing$ L, Andersen LB, Wennlöf a H, Sardinha LB, Harro M, Froberg K, et al. Graded associations between cardiorespiratory fitness, fatness, and blood pressure in children and adolescents. Br J Sports Med. 2006;40(1):25$29-29$.

6. Nielsen GA, Andersen LB. The association between high blood pressure, physical fitness, and body mass index in adolescents. Prev Med. 2003;36(2):229_ 34.

7. Juhola J, Oikonen M, Magnussen CG, Mikkilä V, Siitonen N, Jokinen E, et al. 
Childhood physical, environmental, and genetic predictors of adult hypertension:

The cardiovascular risk in young finns study. Circulation. 2012;126(4):402-9.

8. Franklin SS, Pierce GL. Cardiorespiratory fitness and the attenuation of agerelated rise in blood pressure: An important role for effective primordial prevention. J Am Coll Cardiol. 2014;64(12):1254-6.

9. Kvaavik E, Klepp K-I, Tell GS, Meyer HE, Batty GD. Physical fitness and physical activity at age 13 years as predictors of cardiovascular disease risk factors at ages 15, 25, 33, and 40 years: extended follow-up of the Oslo Youth Study. Pediatrics. 2009;123(1):e80-6.

10. Oliveira-Santos J, Santos R, Moreira C, Abreu S, Lopes L, Agostinis-Sobrinho C, et al. Ability of Measures of Adiposity in Identifying Adverse Levels of Inflammatory and Metabolic Markers in Adolescents. Child Obes. 2016;12(2):135-46.

11. Agostinis-Sobrinho C, Santos R, Moreira C, Abreu S, Lopes L, Oliveira-Santos $\mathrm{J}$, et al. Association between serum adiponectin levels and muscular fitness in Portuguese adolescents: LabMed Physical Activity Study. Nutr Metab Cardiovasc Dis. 2016;6(26):517-24.

12. Leger LA, Mercier D, Gadoury C, Lambert J. The multistage 20 metre shuttle run test for aerobic fitness. J Sport Sci. 1988;6(2):93-101.

13. Tomkinson GR, Lang JJ, Tremblay MS, Dale M, LeBlanc AG, Belanger K, et al. International normative $20 \mathrm{~m}$ shuttle run values from 1142026 children and youth representing 50 countries. Br J Sports Med. 2016;doi:10.1136/bjsports2016-095987.

14. Ruiz JR, Cavero-Redondo I, Ortega FB, Welk GJ, Andersen LB, MartinezVizcaino V. Cardiorespiratory fitness cut points to avoid cardiovascular disease 
risk in children and adolescents; what level of fitness should raise a red flag? A systematic review and meta-analysis. Br J Sports Med. 2016;50:1451-1458.

15. McCrindle BW. Assessment and management of hypertension in children and adolescents. Nat Rev Cardiol. 2010;7(3):155-63.

16. Williams JS, Brown SM, Conlin PR. Blood-pressure measurement. N Engl J Med. 2009;360(5):e6.

17. Williams B, Poulter NR, Brown MJ, Davis M, McInnes GT, Potter JF, et al. Guidelines for management of hypertension: report of the fourth working party of the British Hypertension Society, 2004-BHS IV. J Hum Hypertens. 2004;18(3).

18. Ribeiro C, Guerra S, Ph D, Twisk JWR, Ph D. Physical activity and biological risk factors clustering in pediatric population. Prev Med. 2004;39(3):596-601.

19. Camhi SM, Kuo J, Young DR. Peer Reviewed: Identifying Adolescent Metabolic Syndrome Using Body Mass Index and Waist Circumference. Prev Chronic Dis. 2008;5(4).

20. Currie C, Molcho M, Boyce W, Holstein B, Torsheim T, Richter M. Researching health inequalities in adolescents: The development of the Health Behaviour in School-Aged Children (HBSC) Family Affluence Scale. Soc Sci Med. 2008;66:1429-36.

21. Lohman TG, Roche AF, Martorell F, Martorell R. Anthropometric standardization reference manual. Human Kinetics Book:Champaign, IL,. Champaign IL: Human Kinetics Book; 1991.

22. Cole TJ, Lobstein T. Extended international (IOTF) body mass index cut-offs for thinness, overweight and obesity. Pediatr Obes. 2012;7(4):284-94.

23. Ruiz JR, Castro-Piñero J, España-Romero V, Artero EG, Ortega FB, Cuenca MM, et al. Field-based fitness assessment in young people: the ALPHA health- 
related fitness test battery for children and adolescents. Br J Sports Med. $2011 ; 45: 518-24$.

24. Tanner JM, Whitehouse RH. Clinical longitudinal standards for height, weight, height velocity, weight velocity, and stages of puberty. Arch Dis Child. 1976;51(3):170-9.

25. Janz KF, Dawson JD, Mahoney LT. Increases in physical fitness during childhood improve cardiovascular health during adolescence: the Muscatine Study. Int J Sports Med. 2002;23 Suppl 1:S15-21.

26. Diaz KM, Shimbo D. Physical activity and the prevention of hypertension. Curr Hypertens Rep. 2013;15(6):659-68.

27. Sallis JF, Owen N, Fisher EB. Ecological models of health behavior. 5th ed. Sa. Health Behavior and Health Education: Theory, Research, and Practice. JosseyBass; 2015. 43-64 p.

28. Pozuelo-Carrascosa DP, Sánchez-López M, Cavero-Redondo I, Torres-Costoso A, Bermejo-Cantarero A, Martínez-Vizcaíno V. Obesity as a Mediator between Cardiorespiratory Fitness and Blood Pressure in Preschoolers. J Pediatr. 2017;182:114-9.

29. Díez-Fernández A, Sánchez-López M, Nieto JA, González-García A, MiotaIbarra J, Ortiz-Galeano I, et al. Relationship between cardiorespiratory fitness and blood pressure in young adults: a mediation analysis of body composition. Hypertens Res. 2017;40(5):511-5.

30. Kannel WB, Brand N, Skinner JJ, Dawber TR, Mcnamara PM. The relation of adiposity to blood pressure and development of hypertensionThe Framingham Study. Ann Intern Med. 1967;67(1):48-59.

31. Sorof J, Daniels S. Obesity hypertension in children: A problem of epidemic 
proportions. Hypertension. 2002;40(4):441-7.

32. Sundstrom J, Neovius M, Tynelius P, Rasmussen F. Association of blood pressure in late adolescence with subsequent mortality: cohort study of Swedish male conscripts. Br Med J. 2011;342:d643.

Figure 1- Differences on blood pressure indexes at follow-up by cardiorespiratory fitness levels at baseline.

Model 1: adjusted for age, sex, height, pubertal status, socioeconomic status (at baseline) and additionally, adjusted for its corresponding baseline levels.

Model 2: Model 1 additionally adjusted for waist circumference at baseline.

${ }^{\text {a }}$ Significantly different from Fit group (model 1)

${ }^{\mathrm{b}}$ Significantly different from Fit group (model 2) 
Figure 2- Associations of cardiorespiratory fitness changes (from baseline) and followup of blood pressure indexes.

Model 1: adjusted for age, sex, height, pubertal status, socioeconomic status (at baseline) and additionally, adjusted for its corresponding baseline levels.

Model 2: Model 1 additionally adjusted for waist circumference at baseline.

${ }^{\text {a }}$ Significantly different from Fit group (model 1)

${ }^{\mathrm{b}}$ Significantly different from Fit group (model 2) 
Table 1. Characteristics of study participants.

\begin{tabular}{|c|c|c|c|c|}
\hline & Baseline & Follow-up & Baseline & Follow-up \\
\hline & Girls $(n=349)$ & Girls $(n=349)$ & Boys $(n=385)$ & Boys $(n=385)$ \\
\hline \multicolumn{5}{|l|}{ Characteristics } \\
\hline Age (year) & $14.17( \pm 1.7)$ & $16.16( \pm 1.7)$ & $14.52( \pm 1.8)$ & $16.52( \pm 1.8)$ \\
\hline Weight (Kg) & $52.85( \pm 10.5)$ & $57.7( \pm 10.1)$ & $57.03( \pm 14.1)$ & $64.80( \pm 12.8)$ \\
\hline Height $(\mathrm{cm})$ & $157.3( \pm 0.6)$ & $160.6( \pm 0.5)$ & $163.5( \pm .1 .1)$ & $171.5( \pm 0.7)$ \\
\hline Waist circumference $(\mathrm{cm})$ & $71.9( \pm 9.7)$ & $74.7( \pm 9.3)^{\mathrm{a}}$ & $73.9( \pm 9.7)$ & $77.2( \pm 9.5)^{\mathrm{a}}$ \\
\hline Body mass index & $21.3( \pm 3.6)$ & $22.35( \pm 3.6)$ & $21.07( \pm 3.5)$ & $21.9( \pm 3.5)$ \\
\hline Underweight (\%) & 4 & 4.3 & 5.5 & 6.5 \\
\hline Normal weight (\%) & 68.5 & 69.3 & 69.2 & 72.6 \\
\hline Overweight (\%) & 21.2 & 19.2 & 20.6 & 17.2 \\
\hline Obese $(\%)$ & 6.3 & 7.2 & 4.7 & 3.7 \\
\hline $\begin{array}{l}\text { Breast/genital development: } \\
\leq \mathrm{III} / \mathrm{IV} / \mathrm{V}(\%)^{*}\end{array}$ & $37.5 / 49 / 13.5$ & $6.9 / 52.7 / 40.4$ & $44.1 / 43.1 / 12.8$ & $5.8 / 50.1 / 44.1$ \\
\hline $\begin{array}{l}\text { Pubic hair development: } \\
\leq \mathrm{III} / \mathrm{IV} / \mathrm{V}(\%)^{*}\end{array}$ & $27 / 48.1 / 24.9$ & $3.2 / 39.8 / 57$ & $30 / 52 / 18$ & $2.4 / 41.5 / 56.1$ \\
\hline Heart Rate & $85( \pm 13)$ & $78( \pm 12)^{\mathrm{a}}$ & $83( \pm 14)$ & $73( \pm 13)^{\mathrm{a}}$ \\
\hline Systolic Blood Pressure (mmHg) & $117.32( \pm 12.0)$ & $113.9( \pm 11.9)^{\mathrm{a}}$ & $121.93( \pm 14.5)$ & $121.38( \pm 12.4)$ \\
\hline Diastolic Blood Pressure (mmHg) & $63.98( \pm 7.81)$ & $60.04( \pm 8.3)^{\mathrm{a}}$ & $63.8( \pm 8.25)$ & $61.1( \pm 8.25)^{\mathrm{a}}$ \\
\hline Pulse Pressure & $53.3( \pm 8.12)$ & $53.8( \pm 8.21)$ & $58.04( \pm 9.9)$ & $60.4( \pm 8.4)^{a}$ \\
\hline Rate Pulse Pressure & $10123( \pm 2163)$ & $8933.16( \pm 2163)^{a}$ & $10182( \pm 2386)$ & $8895.20( \pm 2025)^{a}$ \\
\hline $\begin{array}{l}\text { Cardiorespiratory fitness } \\
\text { (Number of Shuttles) }\end{array}$ & $31.05( \pm 15.1)$ & $38.05( \pm 16.8)^{\mathrm{a}}$ & $58.09( \pm 25.1)$ & $71.25( \pm 26.1)^{\mathrm{a}}$ \\
\hline
\end{tabular}

${ }^{a}$ different from baseline values ( $\mathrm{p}<0.05$ for all).

* Pubertal stage according to the criteria of Tanner and Whitehouse (1976) (24). 
Table 2 Unstandardized regression coefficients examining the association between (baseline) cardiorespiratory fitness and Blood pressure indexes (follow-up)

\begin{tabular}{lcccc}
\hline & \multicolumn{4}{c}{ Cardiorespiratory fitness* } \\
\cline { 2 - 5 } Dependent Variable & Model & $\mathrm{R}^{2}$ & $\mathrm{~B}$ & $P$ value \\
Systolic BP & 1 & 0.297 & -0.182 & 0.009 \\
& 2 & 0.300 & -0.126 & 0.047 \\
Diastolic BP & 1 & 0.182 & -0.092 & 0.073 \\
& 2 & 0.181 & -0.088 & 0.113 \\
Pulse Pressure & 1 & 0.245 & -0.096 & 0.073 \\
& 2 & 0.252 & -0.034 & 0.550 \\
Rate Pressure product & 1 & 0.196 & -45.07 & $<0.001$ \\
& 2 & 0.207 & -29.94 & 0.016
\end{tabular}

BP: blood pressure. Model 1; adjusted for age, sex, height, pubertal stage, socioeconomic status at baseline and additionally controlled for the corresponding (dependent) baseline value. Model 2; Model 1 additionally adjusted for waist circumference at baseline 


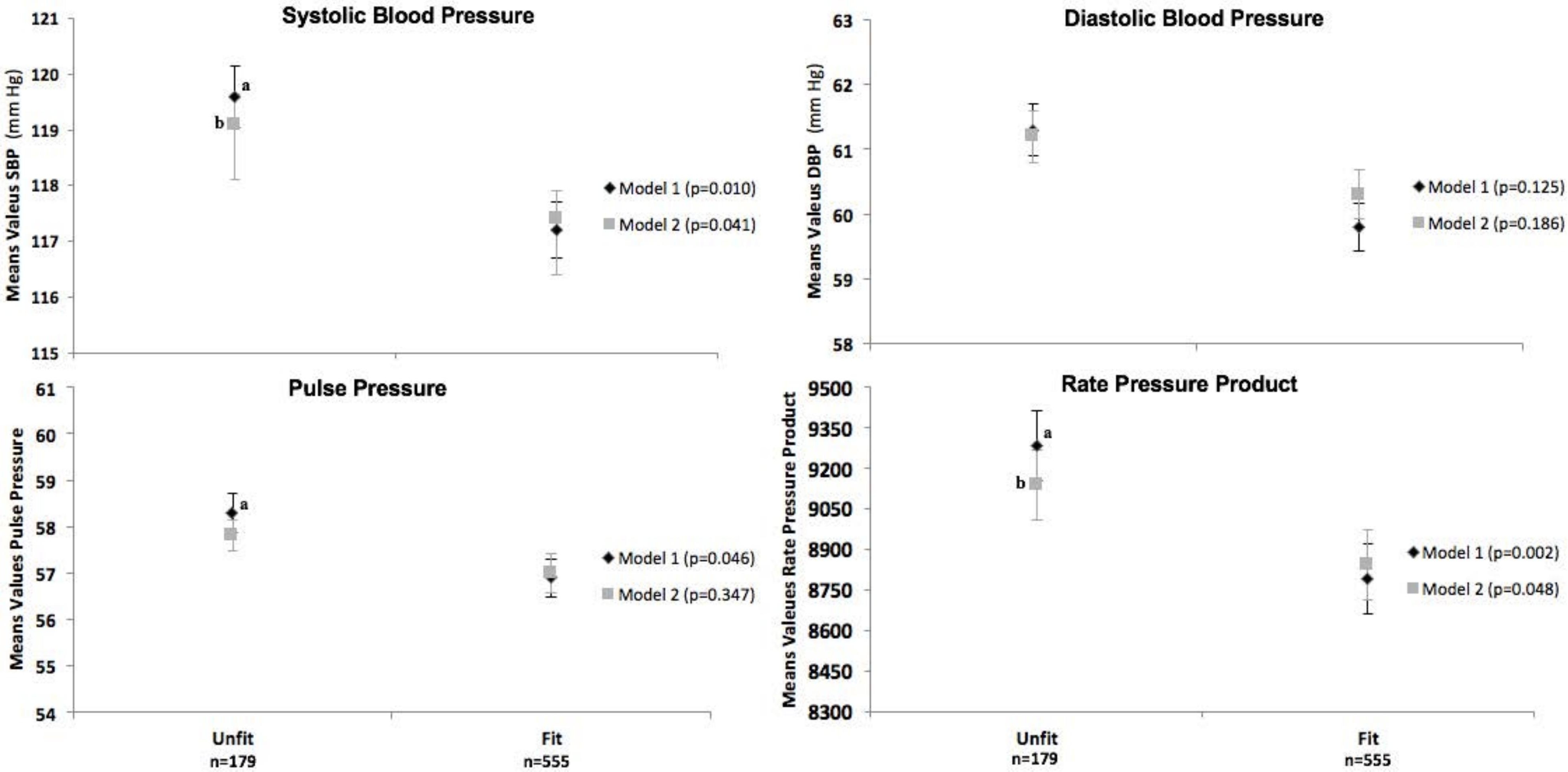




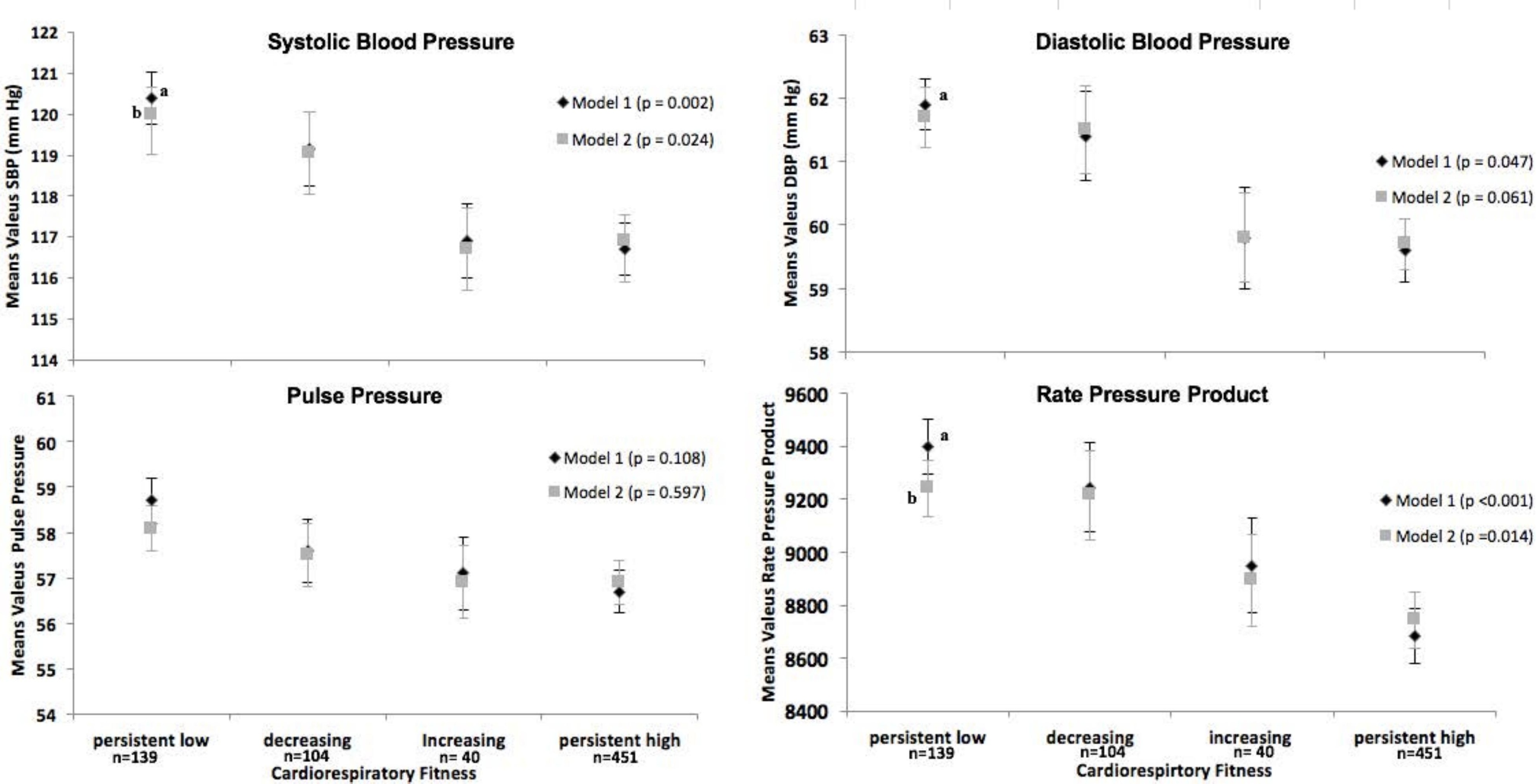

